\title{
La poesía dialectal romañola: traducción y accesibilidad para un lector hispanohablante ${ }^{\bullet}$
}

\author{
Lucia Faraoni •• \\ Università Ca' Foscari Venezia - \\ Universidad Nacional del Litoral
}

\begin{abstract}
Resumen
El trabajo se propone ofrecer las bases teóricas y culturales para una traducción al español rioplatense de algunos poemas en dialecto romañolo, con el fin de redactar una antología de los principales representantes de la corriente literaria de los neodialectales. La parte inicial se dedica en la descripción del plurilingüismo en Italia y en la función de los dialectos, para contextualizar después el nacimiento de la literatura neodialectal y justificar a nivel cultural y sociológico su éxito. La investigación se circunscribe luego a la región Romaña, a la difusión del dialecto de la zona y a los poetas principales: Tonino Guerra, Nino Pedretti, Raffaelo Baldini. Por ende, se describen las técnicas de traducción utilizadas y las principales teorías que justificaron el trabajo a nivel práctico. Como ejemplo se presentan dos poemas traducidos, «I partigièn» de Nino Pedretti y «Viazè» de Raffaello Baldini.
\end{abstract}

Palabras clave:

· traducción · literatura dialectal · plurilingüismo

- Este trabajo es una síntesis de mi tesis, elaborada y defendida en 2015, como cierre del programa de doble titulación en Estudios Ibéricos e Iberoamericanos entre la Università Ca' Foscari Venezia y la Universidad Nacional del Litoral. El presente escrito se propone introducir el tema del plurilingüismo en Italia, de sus expresiones literarias y de la posible traducción y difusión de éstas en español.

- Licenciada en Letras por la Universidad Nacional del Litoral y en la carrera de Lingue e Letterature Europee, Americane e Postcoloniali de la Università Ca' Foscari de Venezia. Sus temas de investigación versan sobre la traducción, la literatura dialectal italiana en traducción y sobre las interrelaciones culturales entre los dos países. Desde el año 2016 colabora en el Portal Virtual de la Memoria Gringa de la FHUC, UNL. 


\begin{abstract}
In this work I motivate, in a theoretical and a cultural perspective, a translation of some poems from Romagna's dialect to «rioplatense» Spanish. My aim is to edit an anthology of the main authors of the "neodialettali» literary movement. At first, I describe multilingualism in Italy and the function of the dialects, in order to contextualize the birth of the «neodialectal» literature and to motivate its success from a cultural and sociological point of view.

Then, I focus my research in the region of Romagna, describing the spread of the dialect in this area and the work of the main authors: Tonino Guerra, Nino Pedretti, Raffaello Baldini.

At last, I explain the translation techniques and the main theories that led the work in a practical way. As examples, I propose the translation of two poems, «I partigièn» from Nino Pedretti and «Viazè» from Raffaello Baldini.
\end{abstract}

\title{
Key words:
}

translation · dialectal literature $\cdot$ multilingualism

\section{El plurilingüismo y su literatura}

Para poder hablar de poesía dialectal es fundamental introducir la compleja cuestión del idioma en Italia. La lengua oficial del país es el italiano. Sin embargo, resulta curioso que ese dato no esté mencionado en la Constitución Italiana ${ }^{1}$. En cambio, el artículo 6 de la Constitución dice: «La República tutela con las normas adecuadas las minorías lingüísticas». Desde un punto de vista histórico-geográfico el país se diferencia por tener una fragmentación étnico-lingüística sin precedentes en las otras realidades europeas. Como explica De Mauro (1983:17-18) esa pluralidad es una característica única para el área arioeuropea teniendo en consideración la reducida dimensión de la Península. Y sólo la India - de superficie catorce veces mayor- es según el estudioso un país con un panorama de mezcla cultural, gentes e idiomas similar al de Italia.

El país se puede entonces definir como «plurilingüe», según la acepción de Weinreich (1974:3-5) por el hecho de que la mayoría de la población habla dos, tres o más idiomas. Por «idiomas» no se alude solamente a las lenguas «extranjeras» (como en las zonas de las minorías lingüísticas históricas: la parte septentrional del país o en las colonias de habla albanés en Molise y/o en Sicilia) sino también a los dialectos, ${ }^{2}$ a las variantes diatópicas, diastráticas y diafásicas. 
En Italia se empieza a definir una clara diferencia entre lengua y dialecto a partir de la confirmación de la supremacía del florentino como idioma nacional, jerarquía creada por los intelectuales a partir del siglo XV con el objetivo de justificar la elección del nuevo italiano sobre la base del prestigio del idioma. Entonces se condenó al dialecto a una posición de subordinación a la lengua «alta».

El llamado «idioma oficial» obtuvo su reconocimiento oficial nada más que hace unos 150 años, así que el país, a pesar de su unidad lingüística burocráticamente aceptada, tiene que enfrentarse con el efectivo y profundo plurilingüismo que sigue todavía bien radicado. Luego de la unidad de Italia, las minorías y los dialectos resultaron un problema político para el conseguimiento de una verdadera cohesión de la población italiana y durante el régimen fascista se intentaron suprimir las variedades lingüísticas, consideradas malerba (esp. «hierba mala») para solucionar el problema del analfabetismo. ${ }^{3} \mathrm{Y}$ a pesar de la tutela de las minorías lingüísticas que estipula la Constitución italiana de 1948, el Estado nunca se ocupó de manera específica de la cuestión del plurilingüismo.

La cuestión de la lengua se relaciona desde siempre con el proyecto de constitución de la identidad: en consecuencia, cuando la cuestión de la identidad empieza a tener un valor político y, en el caso italiano, enfocado en el proyecto de concientización del pueblo a favor de la creación del estado unitario, la lengua —o, mejor dicho, las lenguas - se vuelven, de facto, un instrumento. Las múltiples realidades regionales del país conllevan un código de comunicación de ninguna manera homogéneo. Gracias a las políticas escolásticas (y a la paralela dialectofobia que se desprende de tales políticas), el proyecto de unificación lingüística logrará, ya desde el principio del siglo XIX, un gradual aniquilamiento de los dialectos y de los idiomas minoritarios.

El resultado de esta política lingüística y luego de las políticas económicas durante el boom será una estandarización del italiano, tanto a nivel lingüístico como a nivel cultural. Ese proceso se puede resumir en una única palabra: la globalización. Así lo sentenciaba ya Pasolini:

Fra le altre tragedie che abbiamo vissuto (e io proprio personalmente, sensualmente) in questi ultimi anni, c'è stata anche la tragedia della perdita del dialetto, come uno dei momenti più dolorosi della perdita della realtà (che in Italia è stata sempre particolare, eccentrica, concreta: mai centralistica; mai «del potere»). (Brevini, 1990:45)

Actualmente el uso del dialecto se redujo drásticamente. Sin embargo, los lingüistas modernos afirman que a pesar de que el dialecto no sea ya la lengua primaria de la comunicación se puede hablar en el tercer milenio de una «dialectofonía de retorno" o de una "nueva dialectalidad» en ámbitos como la música de los jóvenes, la publicidad o en las escrituras expuestas (por ejemplo, los graffiti) (Brevini, 1990:45). Berruto sostiene que el lema de nuestro siglo podría ser: «ahora que sabemos hablar italiano, podemos volver a hablar dialecto" (Marcato, 2012:134). O por lo menos, se está perdiendo la idea de que el dialecto obstaculice el contacto entre las personas o con las instituciones o que sea una señal de un nivel cultural bajo. Para ratificar la tesis de Berruto, cito Dardano:

Negli ultimi anni il dialetto ha acquistato un prestigio «serio». È stato respinto il rifiuto del dialetto; si è attenuato l'interesse localistico e ideologicamente spurio. Il dialetto è sempre più 
interpretato come la voce del rapporto paritario, del ricordo, dell'amicizia. (...) Il dialetto riscuote ancora successo nella narrativa recente: soprattutto come fattore di connotazione e di caratterizzazione di ambienti e personaggi. Blasoni e ludismi dialettali ricorrono nel parlato comune e nei media. (Dardano, 2011:53)

Ese es el resultado a nivel sociológico de la gran revolución a nivel cultural literario que se empezó a desarrollar a partir de la segunda posguerra, con el nacimiento de la poesía neodialectal. Hablamos de literatura neodialectal porque el sufijo (neo-) distingue su elemento novedoso. De hecho, sabemos que cada dialecto, a partir de su borrosa fecha de nacimiento, siempre funcionó principalmente como medio de comunicación entre personas de una determinada área lingüística, pero también como expresión literaria de sus hablantes.

No es casual que la poesía neodialectal naciera entonces justo en una época de grandes cambios sociológicos y políticos: los primeros escritos de Tonino Guerra y de Pasolini — los dos padres del dialectalismo del siglo XX — ${ }^{4}$ aparecen hacia 1945 y será a partir del boom de los ' 60 cuando se afirma la nueva corriente. Las décadas de los ' 50 y de los ' 60 se caracterizaron a nivel social y cultural en Italia por una ansiedad y una urgencia por lo nuevo que llegó al nivel exasperante de condena tout court de la cultura del pasado. La difusión de los nuevos modelos dictados por la industrialización y el consumismo, además de la creciente superpotencia de los medios de comunicación masiva, favorecieron la pérdida del policentrismo que caracterizaba el país, destruyendo así aquel mundo que había sobrevivido durante la primera mitad del siglo XX y al cual el poeta dialectal se había aferrado.

Podemos sin dudas afirmar que el nacimiento de la poesía neodialectal consiguió frenar el proceso de silenciamiento al que se veían condenados los dialectos. Tanto a nivel del uso funcional en la comunicación como a nivel de investigación intelectual, las raíces de la lengua volvieron a brotar del cemento de la época post-industrial. Se notó cómo la supresión y la nivelación de las diferencias en nombre de la "homogeneización democrática» había llevado a la destrucción de las culturas originarias que caracterizaban la peculiaridad y la riqueza del país. Por esa misma razón se justifica la vuelta al dialecto como símbolo de la alteridad (Buffoni, 2004:358). Cito a Berman: «Uno de los temas centrales de la cultura de los '70 fue la rehabilitación de la memoria y de la historia étnica como elemento vital para la identidad personal» (en Buffoni, 2004:358). La caracterización del dialecto como idioma de la autobiografía limita así su espacio de acción al plan de la memoria (Brevini, 1990:46).

El autor neodialectal rehabilita su historia personal y, junto a ella, pone en marcha una serie de cuestiones de identidad extensibles al completo sistema-país. Este proceso ve su originalidad en el uso de un idioma que geográficamente pertenece a una "pequeña patria», o sea a la prolongación del mundo interior del poeta: es el idioma de su casa natal — la capital de esa patria—, y de aquel espacio reconocido y familiar - el barrio, la contrada, el valle, cualquier otro lugar que se limita por el alcance de la mirada — que comparte sus «imágenes lingüísticas». 


\section{La poesía neodialectal romañola}

El término "Romaña» se utiliza para definir el territorio geográfico, histórico y lingüístico que ocupa la parte oriental de la región administrativa Emilia-Romaña. El nombre Romagna, deriva a pesar de la distancia geográfica e histórica, de Roma. De hecho, la Romagna ocupaba la última extremidad del imperio romano de occidente (Balzani, 2001:25-26). La Romaña nunca conoció una coincidencia entre «espacio político institucional» y "espacio regional»: de hecho, los funcionarios bizantinos, el Papa, Napoleón y el Estado unitario no se preocuparon nunca por recortar el territorio sobre la base de una preexistente entidad típicamente romañola (Loporcaro, 2009:3-4). Por esta razón, la Romańa no es una región administrativa independiente, sino un territorio que se diferencia en la parte oeste de la región a la que pertenece (Emilia) por cuestiones básicamente culturales y lingüísticas. El hecho de ser romañolos era entonces una expresión social y solamente en el momento en que la tradición empezó a ponerse "negro sobre blanco", o sea cuando se empezaron a imprimir obras de tipo folclórico, la expresión social pudo volverse "memoria cultural». 5

En la época actual, tal como ya ocurrió en etapas históricas pasadas, cuando se habla de un territorio no reconocido oficialmente se corre el riesgo de minimizar las riquezas locales a un vicioso sentimentalismo folklórico, que en muchas ocasiones se volvió punto de partida de peligrosos nacionalismos. Es importante salvar el concepto de las culturas territoriales de este error de interpretación.

En la revolución de la poesía dialectal de la segunda mitad del siglo XX, los autores romañolos lograron evitar el riesgo sentimentalista y por esa razón pudieron ganar un lugar especial en el panorama literario de la época. Además, una explicación de tal éxito puede encontrarse en la peculiaridad de ese área que todavía mantenía su dialecto en la comunicación cotidiana.

Los principales autores de esa corriente literaria pertenecen a un área determinada de la región que encuentra su centro en Santarcangelo, un pueblito recostado en las colinas de la provincia de Rimini que mira hacia el mar. Allá, en los primeros años de la posguerra, se reunían alrededor del bar «Trieste» los grandes nombres de Tonino Guerra (famoso coguionista de Fellini), Raffaello Baldini, Nino Pedretti, Giuliana Rocchi y Gianni Fucci, para hablar de literatura, arte, cine, política y música. A los ojos de los paisanos de un pueblecito de campo como Santarcangelo, estas charlas debían sonar bastante exóticas y extravagantes y fue por eso que pronto renombraron sarcásticamente al grupo «E” circal de giudéizi» («el grupo de la sabiduría») (Ricci, 2007:XIII).

Un año crucial para la literatura dialectal romañola es 1972, cuando se edita la obra I bu de Tonino Guerra. Como ya explicamos, Guerra fue uno de los precursores de la poesía neodialectal junto con Pasolini y representa la chispa primaria para la creatividad del grupo de Santarcangelo; Guerra, a través de la rehabilitación del dialecto como materia de literatura, amplió su ámbito de «acción» fuera del uso exclusivamente oral. El poeta empezó a componer poemas en dialecto durante sus años de detención en un campo de concentración nazista, tal como explica en una entrevista: 
Ho cominciato a scrivere poesie al tempo della mia prigionia in Germania. Piacevano molto agli amici romagnoli e il dottor Strocchi le trascriveva nel suo quadernetto di appunti. Senza dubbio furono di grande aiuto anche a me perchè costituirono un forte motivo di evasione (...). I Scarabócc rappresentavano la storia di un giovane affidato alla propria solitudine. E non poteva essere diversamente se si pensa che il rinchiudermi nel mio bozzolo costituì l'unica difesa durante il tempo della prigionia. (Brevini, 1990:259)

\section{La traducción del dialecto al español rioplatense: el caso de Nino Pedretti y Raffaello Baldini}

$\mathrm{El}$ interés por investigar sobre la cultura de los orígenes es un proceso histórico cíclico y es la esperanza de rencontrarse con la propia identidad, fuera de las leyes de la masificación global que nos manejan en todo ámbito. ${ }^{6} \mathrm{El}$ momento de crisis económica y de identidad lleva el ser humano a mover su atención desde lo global a lo personal, concentrándose en los aspectos más acogedores de su "pequeña patria» (Brevini, 1987:XV).

La elección de traducir a un idioma extranjero la literatura de una lengua «menor» es un doble desafío: por un lado porque pertenezco a la segunda generación de dialectófonos que no considera el dialecto su lengua materna, sino que es una adquisición posterior, cuando no directamente una elección expresiva; por otro lado, por la decisión de buscar equivalentes expresivos del texto dialectal en una variante diferente del español peninsular, el argentino, en todos sus matices locales, de registro, etcétera.

La experiencia como estudiante extranjera en Santa Fe me brindó muchas ocasiones para reflexionar sobre la cultura italiana y su influjo en muchos ámbitos de la cultura argentina. De forma especial en la zona de Santa Fe, donde se radicó un gran número de inmigrantes italianos que dejaron un rastro indeleble en las costumbres y en la lengua de la población, hasta el punto que siguen operantes asociaciones de las regiones italianas que más representantes tenían en el territorio. Por lo que respecta a la operación traductiva cito a Édouard Glissant (Glissant, 1998:33) cuando dice que el traductor de una lengua minoritaria tiene que abandonar el monolingüismo, que es el fetiche de la lengua mayor y trabajar en presencia de todos los idiomas del mundo. Es decir subvertir el idioma mayor, no a través de la síntesis, sino a través de aperturas lingüísticas que permitan relaciones entre las lenguas: de dominación, connivencia, absorbimiento, erosión, tangencia etc.

Lo que puede lograr el traductor de una lengua menor es construir una puerta para la alteridad, un diálogo entre la lengua de llegada y registrar lo extraño del texto extranjero: gracias a eso, se favorece la superación del escepticismo de quienes abandonaron aquel código considerado grosero y también el despertar de la atención de las generaciones a las que no se transmitió el idioma menor (Nadiani, 2006:8). El fin último del traductor menor será entonces el de retardar el inevitable proceso de patoisement, ${ }^{7}$ intentando insertarse en la cultura de referencia del mundo de hoy, profundamente estandarizada y al alcance de todos.

Además, el traductor tiene que poner especial atención en los aspectos no verbales que caracterizan al dialecto. El romañolo es un idioma con un aspecto performativo muy consistente, por el hecho de haber nacido, como la mayoría de los dialectos, en la esfera de la oralidad. Piénsese, por ejemplo, en un poema cualquiera de Raffaello 
Baldini: es raro pensar que el texto se dirija a un lector, más bien hay que pensar que nació de una lectura en voz alta, de hecho, para una actuación.

El desafío del traductor está justamente en la evaluación del potencial teatral, o sea en la relación semiótica entre signos verbales y signos no verbales (o estructuras de la performance) y en intentar una recreación de ese potencial teniendo en cuenta la imposibilidad de reproducir en la lengua de llegada todos los significados del idioma de partida, sobre todo los que pertenecen a un complejo de signos comunicativos no verbales (Totzeva, 1999:81).

En nuestro caso, el objetivo del trabajo es proveer el lector de un texto-meta que refleje de la manera más inalterada posible las marcas de identidad del texto original. Se trata entonces de una traducción "de servicio», concentrada en el aspecto lingüístico. Es fundamental subrayar ese punto porque resultaría casi imposible llegar a traducciones que sean completamente fieles a las peculiaridades performativas de unos poemas tan fuertemente caracterizados por la marca de la oralidad típica del dialecto romañolo: a pesar de ese límite, la elección del español rioplatense pudo solucionar suficientemente la congruencia de los dos mundos lingüísticos.

Se eligió al español rioplatense porque es un idioma extremadamente dúctil y multiforme. La curiosidad hacia su expresividad y hacia los elementos colaterales del discurso llevaron a prestar atención y a comparar las cuestiones relativas a la fonética, a la pragmática y a la mezcla sociolingüística del español rioplatense con el dialecto romañolo.

Esta comparación no tuvo como objetivo el de individuar analogías formales o gramaticales particulares, sin embargo, se encontró en tal operación una correspondencia a nivel de expresividad personal: los sonidos y el léxico rioplatense tienen un potencial performativo equiparable con el dialecto romañolo y de ahí surge el proyecto de vestir la poesía dialectal de un nuevo idioma. El resultado a nivel concreto se nota principalmente en el uso de los pronombres y de la conjugación de los verbos en relación a esos pronombres, o sea el fenómeno del Voseo y de la tercera persona plural «Ustedes» y también en la elección de un léxico adaptado al lunfardo rioplatense, sobre todo para las traducciones de Baldini, las cuales necesitaban un dinamismo que recalcara los matices propios de lenguaje oral y más «callejero».

El método de abordaje al texto fue el de intentar lograr una traducción que no perdiera de vista el texto de partida, dejando una cierta libertad limitada a los casos en que se encontraba un correspondiente cultural argentino equivalente a la imagen dialectal. Se intentó, dentro de las posibilidades, dejar trabajar la empatía que se percibe entre los dos idiomas, esperando lograr el efecto performativo de la oralidad del dialecto en el texto de llegada. A nivel métrico no se consiguieron resultados equivalentes, ni tampoco a nivel fonético (rimas, asonancias, etc.). El enfoque se concentró sobre todo en la reproducción de imágenes, confiando en la potencia figurativa de los textos dialectales. Al hablar de «fidelidad» con el texto y con la cultura romańola no se excluye la posibilidad de re-crear en la lengua de llegada el potencial comunicativo del dialecto. Cito a Nadiani:

Insomma, il minore [el dialecto] non è sostanza inalterata e inalterabile né definitivamente museificata, né, tantomeno, sostanza a sé stante, per quante istanze di autocoscienza, diversità e autonomia rivendichi, ma rientra in una relazione osmotica con il relativo maggiore e con la lingua-mondo. (Nadiani, 2005:s/d) 
A pesar de que generalmente no se considere el español rioplatense como un idioma "mayor», se ve la posibilidad de que algunas imágenes del dialecto puedan funcionar en esta variante del español y que hasta puedan enriquecerse. En la poesía neodialectal la «negociación» parte del momento de la composición misma: el autor escribe sobre materia muerta (o moribunda), en una lengua que está en la misma condición de precariedad; dirige los versos en lengua original a un público que, como él, tuvo solamente una parcial experiencia directa del mundo descripto. Para ampliar el acceso al texto provee a una autotraducción o a una traducción en italiano y en ese momento la cuestión de la «Otredad» toma las características que asume luego en la traducción a cualquier otra lengua: el traductor debe saber construir un camino de acceso a la obra por parte de los receptores que no manejan la misma galería de imágenes y sentidos.

La traducción en el presente trabajo se inserta perfectamente en la investigación del comparatismo actual, en cuanto se ubica en una posición de intermediación entre universos literarios distantes. La traducción, al convertirse en una problemática central de las líneas teóricas que intentan repensar los límites asignados a los nacionalismos literarios, permite leer en/desde el paradigma babélico con una perspectiva comparada, haciendo visible que

las continuidades y discontinuidades de la literatura se constituyen en condiciones supranacionales, por lo que la problemática de la traducción aparece como un modo fundamental de ocurrencia de los fenómenos culturales y operación central en la constitución de los paradigmas literarios del S. XX. (Crolla, 2003:129)

Por lo que se refiere al registro, se intentó no sabotear los textos originales enriqueciéndolos con un léxico más alto para obtener un mayor lirismo: la elección de un registro medio-bajo sirve al texto de llegada para establecer un contacto directo con el objetivo de todo poeta dialectal. De otra manera, se habría corrido el peligro de traicionar la voz auténtica de los protagonistas de la poesía: gente humilde que se expresa con un habla tan sencilla, como complejos son los sentimientos que expresa. A razón de eso, no se censuraron de ninguna manera las expresiones más corporales o las malas palabras del texto en dialecto, por no desemantizar su intensa expresividad.

A nivel morfológico procuramos mantenernos muy atados al texto original, sobre todo en la traducción de los tiempos verbales, teniendo en cuenta las diferencias de uso entre el dialecto y el español (por ejemplo, para traducir las frases en pasado que generalmente en romañolo se expresan el pasado perfecto compuesto, en español se optó por el pasado perfecto simple).

La traducción de topónimos específicos y de nombres propios permaneció invariada, aclarando con una nota a pie de página sus significados en los casos en que tuvieran un sentido semántico no perceptible inmediatamente por el lector hispanófono o, en general, no dialectófono.

Para traducir los juegos de palabras o las fórmulas populares se buscaron, donde fue posible, equivalentes típicos del lenguaje argentino o de sus jergas, a pesar de subvertir la imagen inicial. A nivel de puntuación se trató de mantener la original aun cuando eso afectara a la inmediata comprensión del texto. La puntuación o su ausencia forman parte del ritmo de los poemas y tiene que ver con las características propias de oralidad, por lo tanto, pareció funcional elegir esa opción. Sin embargo, 
cuando se notó que la fidelidad a la versión original estorbaba de manera excesiva el sentido del texto de llegada, se optó por una modificación.

Se presentan dos de las traducciones, en formato bilingüe; dialecto romañolo y en español rioplatense, como resultado del trabajo realizado. El primero, I partigièn, es uno de los poemas más famosos de Nino Pedretti, autor cumbre de la poesía neodialectal, el cual pudo lograr un éxito a nivel nacional gracias a su primera antología Al vòuși. Poesie romagnole de 1975 (Edizioni del Girasole, Ravenna). La poesía habla de los protagonistas de la Resistencia antifascista, los partisanos, pero lo hace de forma original e inesperada: lo que se desprende de sus palabras no es la típica ceremonia a la Patria, sino una intensa nostalgia por los años perdidos en batalla, una advertencia a las generaciones futuras.

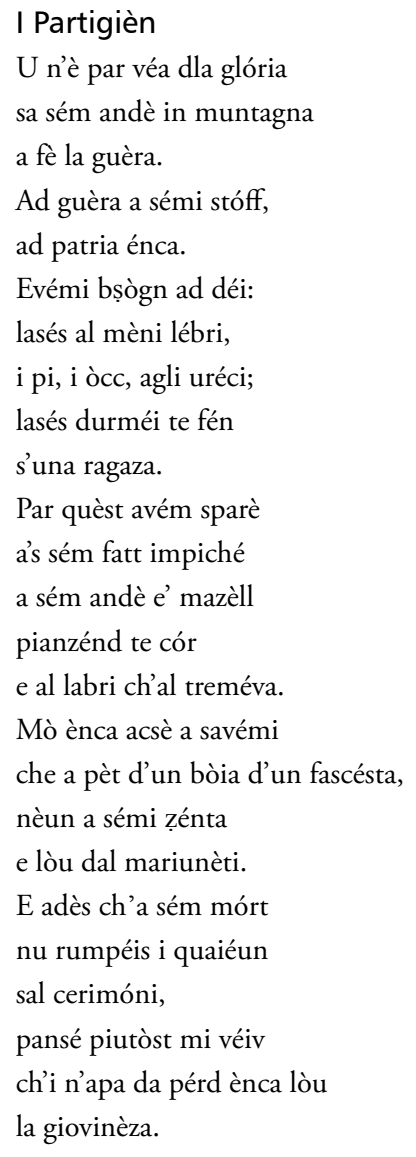

\author{
Los partisanos \\ No es por la gloria \\ si fuimos a la montaña \\ a hacer la guerra. \\ La guerra nos cansó, \\ la patria también. \\ Necesitábamos decir: \\ déjennos las manos libres, \\ los pies, los ojos, las orejas; \\ déjennos dormir sobre la paja \\ con una chica. \\ Por esto disparamos \\ dejamos que nos ahorcasen \\ que nos mandasen al matadero \\ llorando en el corazón \\ y los labios temblando. \\ Pero, aun así, sabíamos \\ que frente a una mierda de fascista, \\ nosotros éramos personas \\ y ellos marionetas. \\ $\mathrm{Y}$ ahora que morimos \\ que no nos hinchen las bolas \\ con ceremonias, \\ mejor piensen en los vivos \\ que no tengan ellos también que perder \\ la juventud.
}

El otro poema seleccionado se distancia mucho del contenido ideológico del precedente, pero es muy apreciable para entender el concepto de teatralidad y de oralidad del dialecto romañolo. Además, en sus contenidos exasperadamente irónicos, brinda al lector extranjero una colorida descripción del universo-pueblo romañolo, en su envidiable ignorancia de lo ajeno. 


\section{Viazè}

Mo viaza tè, mè a stag bèn dò ch’a so, ch'i vèn da fura, aquè, pu u i è Suièn, Vròcc, la Pargàia, ch'a n 'i so mai stè ma la Pargàia, gnenca tè? Mo 'lòura csa vèt zarchè vaièun, che me sno e' lèt furistir, e' cuscéin, che sa n'ò e' mèi, pu tòtt, $t$ vè vèa se sòul, t'arèiv ch'e' piòv ta $\mathrm{n}$ cnòss niscèun, $\mathrm{u}$ t tòcca dmandè sèmpra, e al gambi quand l'è nòta, vdài e' mond?

che dop $\mathrm{t}$ si piò pataca ca nè préima, a m’arcórd Curio, sa che viàz a Lòndra, 'na boba, pu l'è tòuran, e e' dè dop a zughémmia bucètti, ch'e' pareva ch' fóss stè a San Véid, e adès dis ch'e' va in Kenia,

u i vó una bèla vòia, e tè dú vét? A Montecarlo e a Nizza? T’é capéi, e tótt'la Costa Azzurra, quant t sté fura? dis dè? mo 's' ut ch'a próva, ch'a 1 so zà, 'ta bón, fè la valéisa,

purtésla dri, che mè la dmènga in piaza u m dà dan e' giurnèl, e pu e' magnè, u m géva Curio, tótta roba frétta, una pózza, l'agnèll sla marmelèda, i spaghétt ch'i i bai dri e' cafelàt, e mè ch'a so un viziéd, no, gnénca zcòrrni, a stagh ma chèsa méa, piò bén che mai,

che pu a viàz ènca mè, aréiv da Carghín, a vagh me zugh dal bòci,

ch'i n zuga piò niseun, l'é tòtt pin 'fòi, mo mè $\mathrm{u} \mathrm{m}$ pis ènca i póst ch'u $\mathrm{n}$ suzéd gnént, dréinta u s sint sunè un flipper, i pasarótt ch’i era scap véa i artòurna, $\mathrm{u}$ i è che manifesst sémpra spandléun, me méur 'd Canzola, "Viva...», viva chè? E léu e’ réid, csa réidti? che d'instèda quant a vèggh chi sgraziéd, la Roca, l'Èrch, la Piva, tótt sudéd, mè 'lè avrébb vòia da fermèi, vní sa mè, mi Capuzéin, e' zéir dla méura, pièn, tramèza l'erba, e d'ogni tènt punsès, u i è un rapètt, basta slunghè una mèna, dal suséini piò dòulzi ca nè e' mél, i frè i n li còi, pu, vérs Savgnèn, e' vièl,

\section{Viajar}

Y viajá vos, yo estoy bien acá,

hasta vienen de afuera, acá, luego está Sogliano, Verucchio, Perticara ${ }^{1}$ y eso que nunca estuve en Perticara, ¿Ah, vos tampoco? Y entonces qué es lo que andás buscando por ahí,

decí que yo, ya con estar en una cama ajena, la almohada, si no tengo lo mejor... Y todo eso, salís con el sol, llegás y llueve, no conocés a nadie, tenés que preguntar por todo, y las piernas al final del día...

¿ver el mundo?

al final terminás siendo más boludo que antes, me acuerdo de Curio, con eso del viaje a Londres, un garrón, y cuando a la vuelta, y el día después jugábamos a las bochas, parecía que hubiera estado en San Vito, y ahora dice que se va a Kenia,

no sé de dónde sacan las ganas, y vos, ‘a dónde vas? ¿A Montecarlo y a Niza? Mirá vos, y por toda la Costa Azul, ¿cuánto te quedarías? ¿Diez días? Para qué voy a probar, si ya sé, dejá, hacer la valija, cargarla, y eso que a mí, el domingo en la plaza, me molesta hasta el periódico, y luego la comida, me contaba Curio, lo fríen todo, un mal olor, cordero con mermelada, y con los fideos toman café con leche, es que yo soy un malcriado, no, ni hablar, me quedo en mi casa, que es lo mejor que hay,

al fin y al cabo yo también viajo, llego a lo de Carghín,

voy a jugar a las bochas,

que ya nadie juega más a eso, está todo lleno de hojas,

es que a mí me gustan, de hecho, los lugares en donde no pasa nada, adentro se escucha sonar un flipper, los pajaritos que se habían escapado vuelven, está aquel cartel medio colgando en la pared de Canzola, "Viva..." ¿Pero viva qué? Y él se ríe, ¿Pero de qué te reís? Y durante el verano cuando veo a esos desgraciados, el Castillo, el Arco, la Iglesia, todos transpirados, me entran ganas de pararlos y que vengan conmigo, al monasterio de los Capuchinos, a dar la vuelta a la muralla, despacio, por el pasto, 
di arzipréss, un udòur, e in chèva gnént, u s scapa tla spagnèra, che d'alè, dal vólti, zà ch' a i so, travérs cantír, a cal zò te Marèccia,

un slèrgh, t vé dò ch'u t pèr, e tòtt chi sas, mo u i n'è ch'i à di culéur,

i léus, sòtt'aqua, quèsti l'è al zità!

$\mathrm{O}$ a so balèngh? e piò in là do burdèli

S’un gran maz ad fiéur zal, al réid,

al córr, a pi néud, sóura i sas, mo cmè ch'al fa? y de vez en cuando descansar, hay una subidita, basta con estirar la mano, unas ciruelas...

más dulces que la miel, los frailes no las sacan, y más allá, hacia Savignano, el bulevar, unos cipreses, un perfume, y en el fondo nada, se llega al campo de alfalfa, y de allá, ya que estoy, a veces, por los campos, bajo al Marecchia, ${ }^{2}$

un descampado, te vas a donde querés,

y todas aquellas piedras,

se ven algunas con unos colores...

brillan, bajo el agua, ¡Estas sí que son ciudades! ¿O acaso el raro soy yo? Y un poco más allá, dos nenas

con un gran ramo de flores amarillas se ríen, corren, descalzas, sobre las piedras, ¿…cómo lo hacen?

\section{Notas}

${ }^{1}$ A propósito de eso, la Accademia della Crusca el 18 de octubre 2006 propuso a la Camera dei Deputati, la inserción del italiano como idioma oficial del país, en el artículo 12 de la Constitución. La propuesta fue aprobada por la Camera, pero no por el Senado. Consultado en 6 de marzo de 2015 en: http://www.old.accademiadellacrusca.it/img_usr/ Italiano_in_Costituzione.pdf; costituzione/

${ }^{2}$ El término «dialecto» se utiliza para designar una variedad lingüística no estandarizada, prevalentemente utilizada en ámbito oral en una comunidad local y excluida de un empleo formal e institucional (escuela, administración, etc.) (Loporcaro, 2009:3-4).

${ }^{3}$ Durante la época fascista los dialectos se toleraban en la dimensión privada. Sin embargo, quien los utilizaba en ámbitos públicos (como por ejemplo en el cine y en el teatro o en las obras literarias) estaba perseguido por la ley. En un documento de 1943 se exhortaban los periódicos a «non occuparsi di produzioni dialettali e dialetti in Italia, sopravvivenze del passato che la dottrina morale e politica del fascismo tende decisamente a superare». Las motivaciones de tal acción política se han de buscar en el marco socio-cultural de régimen totalitario y centralizador que, negando cada autonomía local y especificidad regional, aventajaron una cultura nacional exaltadora del mito de Roma y del «Imperio» fascista (Klein, 1986:147-155).

${ }^{4}$ El pasaje de la poesía dialectal a neodialectal se fija con la publicación de dos antologías poéticas: Poesie a Casarsa de Pier Paolo Pasolini (1942) y I scarabócc de Tonino Guerra (1946). Los dos poetas se emanciparon de la tradición vernacular-folclórica para abrirse a una nueva experiencia en dialecto, abierta a las mejores influencias nacionales e internacionales (Brevini, 1990:257). 
${ }^{5}$ «El verdadero salto ideológico, la Romaña lo cumple gracias al "regionalismo a imprenta" (print nationalism, según B. Anderson, Comunità immaginate. Origini e fortuna dei nazionalismi, ed. Manifestolibri, Roma, 1996, pp. 56-59) filtrado por intelectuales, poetas, revistas, industria editorial siempre más productiva de temas etnográficos y folklóricos» (Loporcaro, 2009:18-20).

${ }^{6}$ «Il capitalismo realizza il suo dominio non solo omologando i bisogni e le attese di consumo, ma soprattutto attraverso la risemiotizzazione delle forme culturali identitarie» (en Berardi, 2001:151-152).

7 «Per patoisement si intende, in una situazione di lingue in contatto, l'assunzione da parte dei parlanti una determinata lingua, la svalutazione ufficiale di questa loro lingua, vista come meno prestigiosa e incapace di rinnovamento, e il conseguente abbandono della stessa: essi, in tal modo, condannano a morte la loro lingua, dopo una più o meno lunga agonia della stessa nel braccio della morte» (Nadiani, 2003:s/d).

${ }^{8}$ Pueblitos romañolos.

${ }^{9}$ El río Marecchia.

\section{Referencias bibliográficas}

Balzani, R. (2001). La Romagna. Bologna: Il Mulino.

Berardi, F. (2001). La fabbrica dell'infelicità - New Economy e il movimento del cognitariato. Roma: Derive Approdi.

Berman, M. ([1982] 2004). All That Is Solid Melts Into Air: The Experience of Modernity. En Buffoni, F., La traduzione del testo poetico. Milano: Marcos y Marcos.

Berruto, G. ([2002] 2012). Parlare dialetto in Italia alle soglie del Duemila? Aspetti dell'italianizzazione e «risorgenze» dialettali in Piemonte e altrove. En Marcato, C., Il pluringuismo. Roma-Bari: Laterza.

Brevini, F. (1987). Poeti dialettali del Novecento. Torino: Einaudi.

(1990). Le parole perdute. Dialetti e poesia nel nostro secolo.

Torino: Einaudi.

(2004). Lingue e culture in contatto nella poesia dialettale

del Novecento. En Buffoni, F. La traduzione del testo poetico. Milano: Marcos y Marcos.

Crolla, A. (2013). La traducción como «straduzione». En Traduçōes, 8, 122-142. Florianópolis: Universidade Federal de Santa Caterina Dardano, M. (2011). La lingua della Nazione. Bari: Laterza.

De Mauro, T. (1983). Storia linguistica dell'talia unita. Bari: Laterza. Guissant, É. (1998). Poetica del diverso. Roma: Meltemi.

Guerra, T. (1950). La s-ciuptèda. Faenza: Lega.

KueIn, G. (1986). La politica linguistica del Fascismo. Bologna: Il Molino. Loporcaro, M. (2009). Profilo linguistico dei dialetti italiani. Bari: Laterza. Montanari, M. (2004). Storia dell'Emilia Romagna - 1. Dalle origini al Seicento. Roma: Laterza. 
Nadiani, G. (2006). Spostare la scena. Sul tentativo di aprire il sipario minore sul maggiore: traduzione teatrale e lingue sconfitte. TRAlineaonline translation journal, $8, \mathrm{~s} / \mathrm{d}$.

(2004) Le Alpi tirolesi in Romagna? Alcune note sulla (discutibile) necessità di tradurre il minore col maggiore. En Buffoni, F., $L a$ traduzione del testo poetico (pp. 386 y ss.). Milano: Marcos y Marcos.

Pasolini, P.P. (1975). Scritti corsari. En Brevini, F. (1990) Le parole perdute. Dialetti e poesia nel nostro secolo (pp. 45 y ss.). Torino: Einaudi. Ricci, M. (2007). Al vòuși... de témp. Sulla poesia di Nino Pedretti. En Pedretti, N. Al vòuși e altre poesie in dialetto (pp. VII-XLI). Torino: Einaudi.

Totzeva, S. (1999). The Dramatic Text in Performance and Translation. En Boase-Beier, J. Holman, M. (Ed.) The Practice of Literary Translation. Constraints and Creativity (pp. 88 y ss) Manchester: St. Jerome Publishing.

WeInReich, U. (1974). Lingue in contatto. Torino: Boringhieri.

\section{Faraoni, Lucia}

«La poesía dialectal romañola: traducción y accesibi- 